\title{
Direct Evidence of Estrogen Modulation of Pituitary Sensitivity to Luteinizing Hormone- Releasing Factor during the Menstrual Cycle
}

\author{
C. F. WANG and S. S. C. YeN \\ From the Department of Reproductive Medicine, School of Medicine, \\ University of California at San Diego, La Jolla, California 92037
}

\begin{abstract}
A B S T R A C T To delineate the role of estradiol in the augmented pituitary gonadotropin responsiveness to synthetic luteinizing hormone releasing factor (LRF) seen during high-estrogen phases of the ovulatory cycles (late follicular and midluteal phases), the anti-estrogenic effect of clomiphene citrate (Clomid) on pituitary response to LRF was evaluated during different phases of the ovulatory cycle. Clomid administration $(100 \mathrm{mg} /$ day $\times 5$ days) completely negates the augmented gonadotropin responses to LRF (150 $\mu \mathrm{g})$ during late follicular and midluteal phases observed during the control studies. Thus, a quantitatively and qualitatively similar pituitary sensitivity to LRF during three distinct phases of the menstrual cycle was induced by Clomid treatment that resembles the LRF responsiveness of the male pituitary. The present study demonstrates the pituitary component of the estrogen-induced changes in the sensitivity to LRF. From this and previous data, we conclude that the increases of estradiol secretion associated with the follicular maturation and corpus luteum formation represent a major component of the feedback signal in the modulation of cyclic gonadotropin release occasioned in a large measure by the augmented pituitary sensitivity to LRF.
\end{abstract}

\section{INTRODUCTION}

Although it has been suggested that ovarian estradiol may be responsible for the initiation of midcycle gonadotrpin surge, the mechanism(s) involved remain unclear (1). Circumstantial evidence suggest that gonadal steroids exert a profound influence on the pituitary response to luteinizing hormone-releasing factor $(\mathrm{LRF})^{1}$; an en-

Dr. Wang is a Research Fellow in Reproductive Endocrinology.

Received for publication 25 July 1974 and in revised form 13 September 1974.

${ }^{1}$ Abbreviation used in this paper: LRF, luteinizing hormone releasing factor. hanced pituitary responsiveness to LRF was found during the high-estrogen phase of the menstrual cycle $(2,3)$ and in subjects without ovarian function (4). On the other hand, estrogen administration to levels equivalent to those found at midcycle reduces the pituitary responsiveness to LRF in humans $(5,6)$ as well as in monkeys (7). However, our recent studies have suggested that estradiol exhibits both augmentation and inhibition on the pituitary responsiveness to LRF, which is a time- and dose-related event (8-10). To delineate further the role of estrogen in the feedback modulation of gonadotropin secretion, the effect of an anti-estrogen, clomiphene citrate (Clomid, Merrell-National Laboratories, Division of Richardson-Merrell, Inc., Cincinnati, Ohio), on the pituitary responsiveness to synthetic LRF during different phases of the menstrual cycle was evaluated.

\section{METHODS}

Five regularly menstruating women with a usual cycle length of 27-31 days volunteered for this study. The gonadotropin response to an i.v. bolus of synthetic LRF $(150 \mu \mathrm{g})$ were evaluated serially during the early follicular (day 36), late follicular (day 10-13), and midluteal phases (day 20-24) of separate ovulatory cycles. This was followed by Clomid, (100 mg daily dose) administered for 5 days during these three phases of the cycle, and the gonadotropin responses to the same dose of synthetic LRF were tested on the last day of Clomid treatment. Ovulatory cycles were determined by the presence of $\mathrm{LH}$ surge at midcycle and by an elevation of progesterone level of greater than 5 $\mathrm{ng} / \mathrm{ml}$ during the midluteal phase. During each LRF stimulation, samples were obtained at 15-min intervals for 30 min before and $3 \mathrm{~h}$ after the injection of LRF.

Serum follicle-stimulating hormone (FSH) and luteinizing hormone ( $\mathrm{LH}$ ) concentrations were measured by specific radioimmunoassay and expressed as $\mathrm{mIU} / \mathrm{ml}$ serum, with the 2nd IRP-HMG as standard $(11,12)$. Comparison of relative potency of 2 nd IRP-HMG and pituitary standard LER 907 in the radioimmunoassay system revealed $38 \mathrm{mIU} /$ $\mu \mathrm{g}$ for FSH and $210 \mathrm{mIU} / \mu \mathrm{g}$ for $\mathrm{LH}$. All samples from a serial study were measured in a single assay. The two- 


\section{$\longrightarrow$ CONTROL \\ O-O CLOMIO TREATMENT}
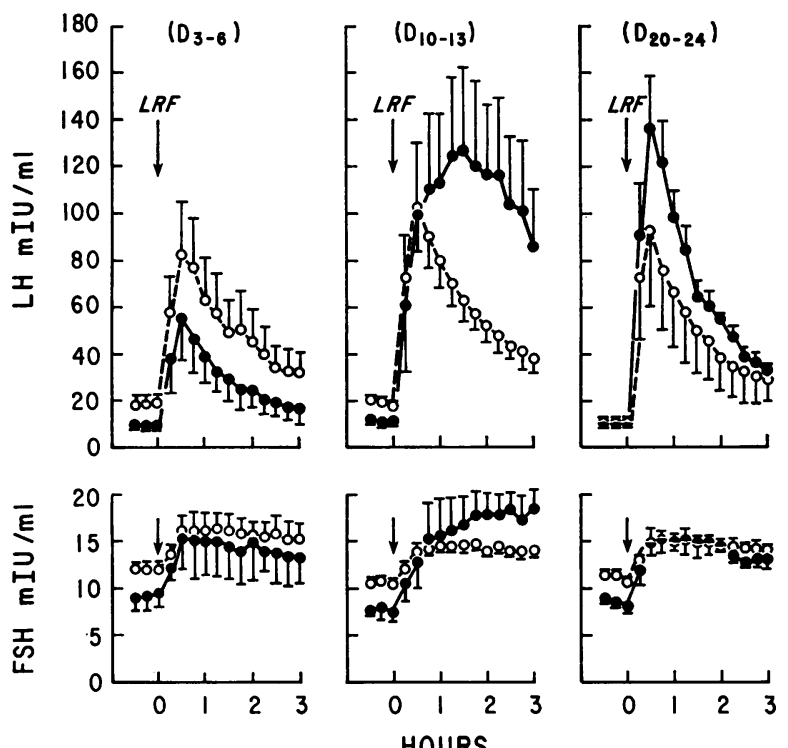

FIGURE 1 Serum $\mathrm{LH}$ and FSH concentrations (mean \pm SE) $30 \mathrm{~min}$ before and $3 \mathrm{~h}$ after LRF (150 $\mu \mathrm{g}$, i.v.) for controls and for Clomid treatment during three different phases of the menstrual cycle.

tailed Student $t$ test and the analysis of variance were used for the statistical analyses.

\section{RESULTS}

When compared with control, Clomid induced a consistent elevation of basal gonadotropin levels in all experiments (Fig. 1). With Student's $t$ test, a statistical significance was found during the late follicular and the midluteal phases for LH $(P<0.05)$ and FSH $(P<$ 0.02 ) but not during the early follicular phase. However, by analysis of variance, basal $\mathrm{FSH}$ and $\mathrm{LH}$ levels in all phases of Clomid-treated cycles were significantly elevated $(P<0.025)$. This finding is consistent with our previous study of the effect of Clomid during the normal menstrual cycle (13).

In control cycles, LRF (150 $\mu \mathrm{g})$ induced a prompt increase in circulating $\mathrm{LH}$ and $\mathrm{FSH}$ levels during all three phases of the cycle studied (Fig. 1). A qualitative and quantitative difference in the maximal rise was observed that was greater for $\mathrm{LH}$ than for $\mathrm{FSH}$; there was more $\mathrm{LH}$ release in response to $\mathrm{LRF}$ during the late follicular and midluteal phases than during the early follicular phase; a delayed and more sustained peak (90 min vs. $30 \mathrm{~min}$ for $\mathrm{LH}, 3 \mathrm{~h}$ vs. $45 \mathrm{~min}$ for FSH) was seen uniquely during the late follicular phase of the cycle. These findings confirm our previous data $(1,2)$. With Clomid treatment, these differences were abolished and an almost identical LRF responsiveness for both
$\mathrm{LH}$ and FSH during all three phases of the cycles was observed.

Because of the elevated basal FSH and $\mathrm{LH}$ levels after Clomid treatment in comparison with control studies, further analyses of percent increment $(\Delta)$ from basal values at zero time in response to $L R F$ revealed a more distinct progressive increase in $\Delta \mathrm{LH}$ between early, late follicular, and midluteal phases (Fig. 2). In clear contrast, Clomid treatment induced a reduction of both $\Delta \mathrm{LH}$ and $\triangle \mathrm{FSH}$ in response to LRF during all three phases of the cycle. These effects were proportionately greater during the late follicular and the midluteal phases, and thus abolished the variation and qualitative differences in response to LRF seen during control studies.

\section{DISCUSSION}

The effect of anti-estrogen action of Clomid on the pituitary responsiveness to LRF during the course of ovulatory menstrual cycle has not previously been evaluated. We have speculated that the increase in pituitary gonadotropin responsiveness during the late follicular phase and during the midluteal phase as compared to the early follicular phase of the cycle is temporally re-

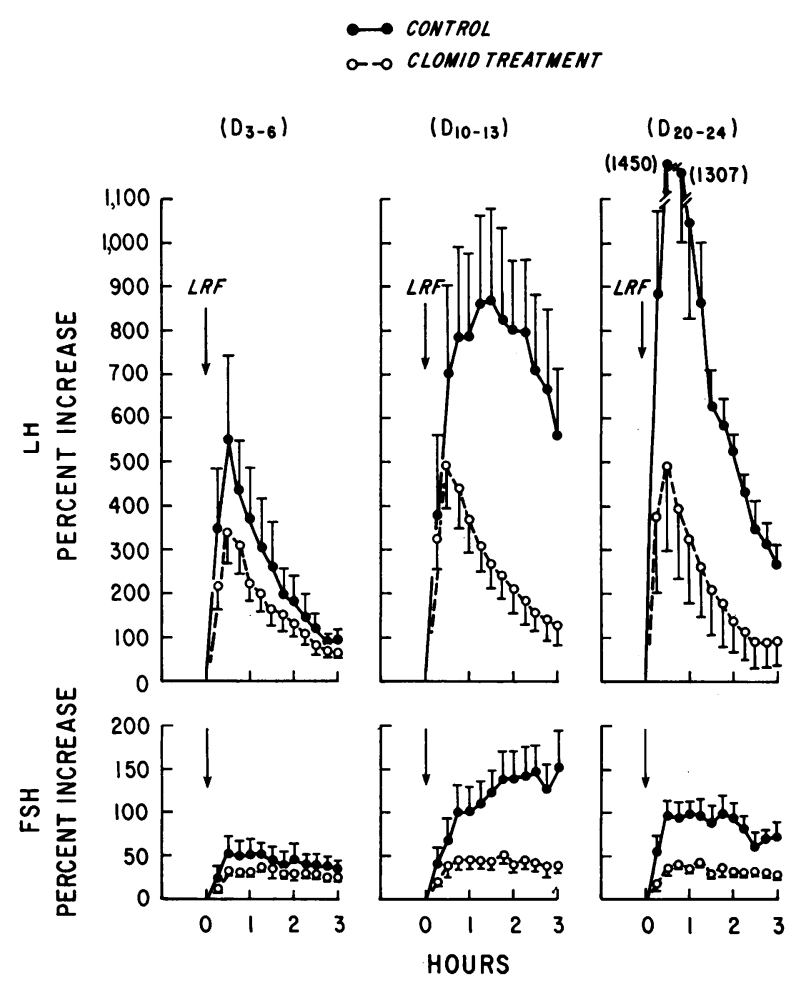

Figure 2 The percent increase (mean \pm SE) above basal levels of serum LH and FSH during the $3 \mathrm{~h}$ after a bolus of LRF (150 $\mathrm{gg}$, i.v.) for control and for Clomid treatment during three different phases of the menstrual cycle. 
lated to a direct feedback action of increasing levels of estradiol $(1,2)$. This interpretation is supported by our observations that estrogen administration promotes pituitary $\mathrm{LH}$ release in response to $\mathrm{LRF}$ with a delayed and sustained time course, similar to that seen during the late follicular phase of the cycle $(9,10)$. Since Clomid exerts an anti-estrogen action by competition of estradiol receptor at the hypothalamic-pituitary sites (14-16), administration of Clomid during different phases of the ovulatory cycle should provide a direct evidence of the role of estradiol in the feedback modulation of pituitary sensitivity to LRF. The present study clearly demonstrate that the variation of gonadotropin responsiveness to LRF during the course of the ovulatory cycle can be completely negated by the administration of Clomid (Figs. 1 and 2). The reduction of pituitary responses to LRF effected by Clomid is proportionately greater during high-estrogen phases of the cycle (late follicular and midluteal phases). In this manner, a quantitatively and qualitatively similar pituitary gonadotropin sensitivity to LRF during three distinct phases of the menstrual cycle was induced that resembles the LRF responsiveness seen in normal male subjects (8).

The precise mechanism(s) involved in the decrease of pituitary sensitivity after Clomid treatment is not entirely clear. Consistent with our present finding is the interpretation that estrogen exerts a direct stimulatory action on the pituitary gonadotrophs and thereby increases sensitivity to LRF, and that Clomid may negate this estrogen effect on the pituitary gonadotropin-producing cells, resulting in a reduced LRF responsiveness. Experimental evidence in rats both in vivo and in vitro (17-20), as well as in humans (9), is rapidly accumulating to support the stimulatory action of a direct estrogen-pituitary feedback. Our recent experiments in humans have afforded a more decisive demonstration in which augmentation of pituitary sensitivity by estrogen can be readily reproduced by the administration in appropriate amounts and duration of estrogen and much smaller doses of LRF in both normal and hypogonadal women (21).

Although our data heightened the relationship of a direct action of estrogen on pituitary gonadotrophs, a concomitant change in endogenous LRF release may have occurred. Although estrogen has shown to inhibit LRF release, preliminary data suggest that rapid increase in estrogen levels may promote LRF secretion (22-24). Thus, the likelihood that the anti-estrogen action of Clomid may reduce the hypothalamic release of endogenous LRF and hence cause a decrease in pituitary gonadotropin sensitivity and/or synthesis cannot be overlooked, but remains to be elucidated. Available evidence suggests that the competition of estradiol recep- tors by clomiphene is greater at the level of pituitary than at the hypothalamus $(14,25)$, and the specific estradiolbinding capacity of the hypothalamus is only one tenth of that found in the anterior pituitary (26). Therefore, the possible contribution of this altered endogenous LRF release may be small. Regardless of this potential contribution of the altered endogenous LRF, possibly effected by Clomid, our present study demonstrates the pituitary component of the estrogen feedback modulation. In the physiological context, it is concluded that the increased secretion of estradiol associated with follicular maturation and corpus luteum formation represents a major component of the feedback signal in the modulation of cyclic gonadotropin output, occasioned in a large measure by the increased pituitary sensitivity to LRF.

\section{ACKNOWLEDGMENTS}

We are grateful to Dr. R. Guillemin for the gift of synthetic LRF and for the excellent technical supervision by Dr. T. Siler. Mr. M. Sigel, Ms. B. Foster, Mr. G. Brink, and Mrs. P. Malcolm provided excellent technical sssistance. We would like to thank Prof. A. Lein for his supervision of statistical analysis of the data.

Antigens and antisera for the radioimmunoassay of $\mathrm{LH}$ and FSH were kindly supplied by the National Pituitary Agency and the National Institute of Arthritis and Metabolic Diseases. 2nd IRP-HMG was kindly supplied by the Medical Research Council, Mill Hill, London.

This work was supported by Rockefeller Foundation Grant RF 70029 and AID/csd/2785.

\section{REFERENCES}

1. Yen, S. S. C., G. VandenBerg, C. C. Tsai, and T. Siler. 1974. Causal relationship between the hormonal variables in the menstrual cycle. In Biorhythms and Human Reproduction. M. Ferin, F. Halberg, R. M. R. Richart, and R. L. Vanderwiek, editors. John Wiley \& Sons, Inc., New York, 219-238.

2. Yen, S. S. C., G. VandenBerg, R. Rebar, and Y. Ehara. 1972. Variation of pituitary responsiveness to synthetic LRF during different phases of the menstrual cycle. J. Clin. Endocrinol. Metab. 35: 931-934.

3. Nillius, S. J., and L. Wide. 1972. Variation in LH and FSH response to LH-releasing hormone during the menstrual cycle. J. Obstet. Gynaecol. Br. Commonze. 79: 865-873.

4. Siler, T. M., and S. S. C. Yen. 1973. Augmented gonadotropin response to synthetic LRF in hypogonadal state. J. Clin. Endocrinol. Metab. 37: 491-494.

5. Keye, W. R., Jr., and R. B. Jaffe. 1974. Modulation of pituitary gonadotropin response to gonadotropin-releasing hormone by estradiol. J. Clin. Endocrinol. Metab. 38: 805-810.

6. Thompson, I. E., J. Arfania, and M. L. Taymor. 1973. Effects of estrogen and progesterone on pituitary response to stimulation by luteinizing hormone-releasing factor. J. Clin. Endocrinol. Metab. 37: 152-155.

7. Krey, L. C., W. R. Butler, G. Weiss, R. F. Weick, D. J. Dierschke, and E. Knobil. 1973. Influences of endogenous and exogenous gonadal steroids on the action 
of synthetic LRF in the rhesus monkey. Excerpta Med. Int. Congr. Ser. 263: 39-47.

8. Yen, S. S. C., R. Rebar, G. VandenBerg, F. Naftolin, H. Judd, Y. Ehara, K. J. Ryan, J. Rivier, M. Amoss, and R. Guillemin. 1973. Clinical studies with synthetic LRF. Excerpta Med. Int. Cong. Ser. 263: 217-229.

9. Yen, S. S. C., G. VandenBerg, and T. M. Siler. 1974. Modulation of pituitary responsiveness to LRF by estrogen. J. Clin. Endocrinol. Metab. 39: 170-177.

10. VandenBerg, G., G. Devane, and S. S. C. Yen. 1974. Effects of exogenous estrogen and progestin on pituitary responsiveness to synthetic luteinizing hormone-releasing factor. J. Clin. Invest. 53: 1750-1754.

11. Yen, S. S. C., O. Llerena, B. Little, and O. H. Pearson. 1968. Disappearance rates of endogenous luteinizing hormone and chorionic gonadotropin in man. J. Clin. Endocrinol. Metab. 28: 1763-1767.

12. Yen, S. S. C., O. Llerena, O. H. Pearson, and A. S. Littell. 1970. Disappearance rates of endogenous folliclestimulating hormone in serum following surgical hypophysectomy in man. J. Clin. Endocrinol. Metab. 30: 325-329.

13. VandenBerg, G., and S. S. C. Yen. 1973. Effect of antiestrogenic action of clomiphene during the menstrual cycle: evidence for a change in the feedback sensitivity. J. Clin. Endocrinol. Metab. 37: 356-365.

14. Igarashi, M., Y. Ibuki, H. Kubo, J. Kamioka, N. Yokata, Y. Ehara, and S. Matsumoto. 1967. Mode and site of action of clomiphene. Am. J. Obstet. Gynecol. 97: 120-123.

15. Kato, J., T. Kobayashi, and C. A. Villee. 1968. Effect of clomiphene on the uptake of estradiol by the anterior hypothalamus and hypophysis. Endocrinology. 82 : 10491052.

16. Roy, S., V. B. Mahesh, and R. B. Greenblatt. 1964. Effect of Clomiphene on the physiology of reproduction in the rats. III. Inhibition of uptake of radioactive oestradiol by the uterus and the pituitary gland of immature rat. Acta Endocrinology. 47: 669-675.

17. Bogdanove, E. M. 1963. Direct gonad-pituitary feed- back: an analysis of effects of intracranal estrogenic depots on gonadotropin secretion. Endocrinology. 73: 696-712.

18. Greeley, G. H., M. B. Allen, and V. B. Mahesh. 1974. Demonstration of a direct effect of $17 \beta$-estradiol on pituitary $\mathrm{LH}$ secretion by the use of an isolated pituitary rat model. Endocrinology. 94: A-152. (Abstr.)

19. Libertun, C., R. Orias, and S. M. McCann. 1974. Biphasic effect of estrogen on the sensitivity of the pituitary to luteinizing hormone-releasing factor. Endocrinology. 94 : 1094-1100.

20. Debeljuk, L., J. A. Vilchez-Martinez, A. Arimura, and A. V. Schally. 1974. Effect of gonadal steroids on the response to $\mathrm{LH}-\mathrm{RH}$ in intact and castrated male rats. Endocrinology. 94 : 1519-1524.

21. Yen, S. S. C., B. L. Lasley, C. F. Wang, H. Leblanc, and T. M. Siler. 1974. The operating characteristics of the hypothalamic-pituitary system during the menstrual cycle and observations of biological action of somatostatin. Recent Prog. Hormone Res. In press.

22. Malacara, J. M., E. Seyler, Jr., and S. Reichlin. 1972. Luteinizing hormone releasing factor activity in peripheral blood from women during the midcycle luteinizing hormone ovulatory surge. J. Clin. Endocrinol. Metab. $34: 271-278$

23. Arimura, A., A. J. Kastin, and A. V. Schally. 1974. Immunoreactive LH-releasing hormone in plasma: midcycle elevation in women. J. Clin. Endocrinol. Metab. 38 : $510-513$.

24. Seyler, L. E., Jr., E. Canalis, and S. Reichlin. 1974 Estrogen stimulated luteinizing hormone-releasing factor (LRF) secretion in hypogonadal males. Clin. Res. 22: 349A. (Abstr.)

25. Maurer, R., and D. Woolley. 1971. Distribution of ${ }^{8} \mathrm{H}-$ estradiol in clomiphene-treated and neonatally androgenized rats. Endocrinology. 88: 1281-1287.

26. Korach, K. S., and T. G. Muldoon. 1974. Studies on the nature of the hypothalamic estradiol-concentrating mechanism in the male and female rat. Endocrinology. 94: 785-793. 